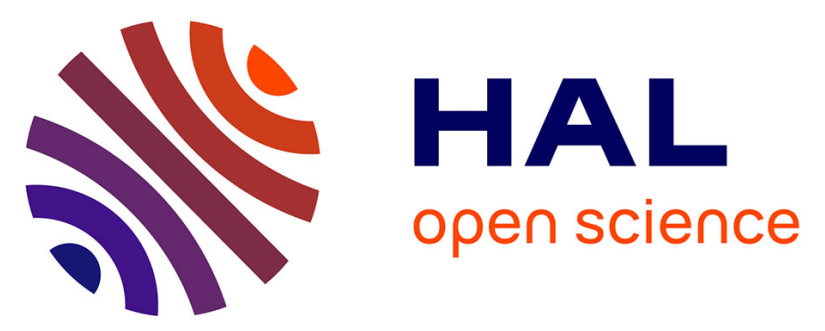

\title{
Pharmacological inactivation of the endothelin type A receptor in the early chick embryo: a model of mispatterning of the branchial arch derivatives.
} Hervé Kempf, Charlotte Linares, Pierre Corvol, Jean Marie Gasc

\section{- To cite this version:}

Hervé Kempf, Charlotte Linares, Pierre Corvol, Jean Marie Gasc. Pharmacological inactivation of the endothelin type A receptor in the early chick embryo: a model of mispatterning of the branchial arch derivatives.. Development (Cambridge, England), 1998, 125 (24), pp.4931-4941. hal-01644348

\section{HAL Id: hal-01644348 \\ https://hal.univ-lorraine.fr/hal-01644348}

Submitted on 22 Nov 2017

HAL is a multi-disciplinary open access archive for the deposit and dissemination of scientific research documents, whether they are published or not. The documents may come from teaching and research institutions in France or abroad, or from public or private research centers.
L'archive ouverte pluridisciplinaire HAL, est destinée au dépôt et à la diffusion de documents scientifiques de niveau recherche, publiés ou non, émanant des établissements d'enseignement et de recherche français ou étrangers, des laboratoires publics ou privés. 


\title{
Pharmacological inactivation of the endothelin type A receptor in the early chick embryo: a model of mispatterning of the branchial arch derivatives
}

\author{
Hervé Kempf, Charlotte Linares, Pierre Corvol and Jean-Marie Gasc* \\ Collège de France, INSERM U36, 3 rue d'UIm, 75005 Paris, France \\ *Author for correspondence (e-mail: gasc@infobiogen.fr) \\ Accepted 5 October; published on WWW 12 November 1998
}

\section{SUMMARY}

In the present study, we have applied an antagonist treatment to the chick embryo in ovo in order to demonstrate and dissect the essential roles of the endothelin type A (ETA) receptor in the embryonic development. We have cloned, sequenced and expressed the cDNA of the chick ETA receptor and shown that its affinity for endothelin antagonists is very similar to that shown by its mammalian counterparts. We have studied the spatiotemporal expression pattern of this receptor by in situ hybridization and shown that there is a high level of its mRNA within the mesenchyme of the branchial arches at E3-E5, in keeping with the direct effect of endothelin-1 (ET1) on the fate of this region of the embryo. Unlike the endothelin type B (ETB) receptor mRNA, ETA mRNA is not expressed in neural crest cells during emigration from the neural tube, but is detected in neural crest-derived ectomesenchyme of the branchial arches. Finally, the functional involvement of this receptor in craniofacial and cardiovascular organogenesis was assessed by selectively inactivating the ETA receptor with specific antagonists applied during the time period corresponding to the expression of the ETA receptor and colonisation of the branchial arches. Embryos treated by these antagonists show a severe reduction and dysmorphogenesis of the hypobranchial skeleton, as well as heart and aortic arch derivative defects. This phenotype is very similar to that obtained in mice by gene inactivations of ET-1 and ETA. These results are observed with ETA antagonists but not with an ETB antagonist, and are dependent on the dose of the antagonists used and on the time of application to the embryo. Altogether, these data strongly show that the ET1/ETA pathway, in chicken as in mammals, is a major factor involved directly and functionally in morphogenesis of the face and heart.

This experimental model of pharmacological inactivation of a gene product described in this study offers a simple and rapid alternative to gene inactivation in mouse. This strategy can be applied to other ligandreceptor systems and extended to compounds of various chemical and functional natures.

Key words: Endothelin system, ETA, Gallus gallus, Neural crest cell, Craniofacial development, Cardiovascular development

\section{INTRODUCTION}

The body plan organisation and morphogenesis of the organs result from the sequential activation and spatio-temporal combinatorial expression of various genes, including transcription factors, growth factors and their associated receptors. Each member of these families play a crucial and specific role in patterning various structures. Thus, whereas the Hox genes are involved in the antero-posterior positioning and are master genes of body plan in vertebrate development (Krumlauf, 1994), members of the basic helix-loop-helix family, for instance, are factors controlling the fate of such lineage as muscles, hematopoietic cells or neurons (Lee, 1997). As to the ligands and associated receptors, they operate mostly through interactions between ligand-producing and target cells, allowing the latter to grow, migrate, condense, differentiate or undertake apoptosis. By gene inactivation, superactivation or antisense inhibition, numerous genes have been shown to participate in the functional development of the head musculature and skeleton (Schilling, 1997), and/or of the inflow and outflow tract of the heart (Lyons, 1996). Unexpectedly among many other factors, the genes of the endothelin system emerged as key factors in patterning these structures by affecting specifically some subsets of neural crest (NC) cells.

Endothelins are a family of peptide hormones with three members, endothelin-1, endothelin-2 and endothelin-3 (ET-1, ET-2 and ET-3) encoded by three distinct genes (Inoue et al., 1989). The mature peptide ET-1 (21 amino acids) was initially characterized by its potent vasoconstrictive properties (N. Yanagisawa et al., 1988). The effects of the ET peptides are mediated through two known distinct specific endothelin receptors. In mammals, based on their binding affinities for the native and synthetic ligands, they have been classified as type A and type B receptors (ETA and ETB). The ETA receptor has a high affinity for ET-1 and ET-2 and a low affinity for ET-3, 
whereas the ETB receptor does not discriminate between the three endothelin isoforms. In mammalian species, both receptors have been cloned and characterized (for a review see Sakurai et al., 1992). These receptors belong to the G-protein coupled receptor family and activate the phospholipase $\mathrm{C}$ pathway, leading to an inositol phosphate accumulation and subsequent $\mathrm{Ca}^{2+}$ release. In non-mammalian classes of vertebrates, an ETA receptor (Kumar et al., 1994) and another atypical receptor, called ETC (Karne et al., 1993), have been cloned in Xenopus, whereas in birds two type B related sequences have been published so far (Nataf et al., 1996; Lecoin et al., 1998).

The targeted gene inactivation of ET-1 results in a significant reduction in size of the mandible and tongue (Kurihara et al., 1994) and in aortic arch malformations and various heart defects (Kurihara et al., 1995a). More recently, a similar phenotype in mice with an inactivated ETA receptor gene was reported (Clouthier et al., 1998). Thus the ET1/ETA signaling pathway is involved in the patterning of cranial and cardiac NC cell-derived structures. Two other components of the endothelin system, ET-3 and ETB, were also inactivated by homologous recombination in mice (Baynash et al., 1994; Hosoda et al., 1994). Null mice for ET3 or ETB genes exhibit severe aganglionose in the distal colon, characteristic of the Hirschsprung's disease. The endothelin converting enzyme (ECE-1), necessary for the maturation of ET-1 and ET-3, has also been inactivated (Yanagisawa et al., 1998a) and the phenotype recapitulated the malformations obtained by the genetic disruption of ET1/ETA and ET-3/ETB pathways.

The chick embryo is a well established experimental model for studying the role of a gene in development, especially for $\mathrm{NC}$ cell derivatives. Thus, to further investigate the exact function of ETA in processes that contribute to the head and cardiovascular organogenesis, we decided to inactivate the ETA receptor in the chick embryo using receptor-type specific antagonists. Although a high degree of similarity between the ET systems in birds and mammals was expected, there was a need to validate the potential of this experimental model in comparing results for the endothelin system with those of mammals.

Here we present a detailed analysis of the molecular structure, pharmacology and early temporo-spatial expression pattern of the ETA receptor in the chick embryo. This first series of experiments permitted the selection of an inhibitor that could antagonize the chicken ETA receptor efficiently and provided evidence of the similarity of the ET system in birds and mammals. These results allowed us to use a strategy of in ovo receptor inactivation of the ET-1-ETA system in the chicken embryo. In ovo, specific blockade of the ETA receptor was assessed by experiments using a specific ETA receptor antagonist, a mixed ETA/ETB antagonist or a specific ETB antagonist, as a control. The data presented here provide independent and complementary evidence that ETA is the receptor of the endothelin system required for normal morphogenesis of the face and cardiovascular system in chick, in the same way as in mammals. In addition, the strategy pursued identified the period of time during which the ET-1/ETA pathway is crucial for the patterning of ectomensenchymal derivatives.

\section{MATERIALS AND METHODS}

\section{Cloning, library screening and sequencing of the chicken ETA receptor (cETA)}

Primers $\mathrm{Aa}$ and $\mathrm{Ba}$ were directed at regions that are the most conserved at the nucleotide level between amphibian and mammalian ETA receptors. The sequences were Aa, 5'-TACCAGAACAAATGTATGAGG-3' and Ba, 5'-GAGGCATGACTGGAAACAATT-3'. cDNA was synthesized from chicken heart RNA, and PCR was performed as follows: 32 cycles of denaturation at $95^{\circ} \mathrm{C}$ for 1 minute, annealing at $50^{\circ} \mathrm{C}$ for 1 minute, extension at $72^{\circ} \mathrm{C}$ for 1 minute, followed by a 10 minute elongation at $72^{\circ} \mathrm{C}$. PCR products of the expected size were TA-subcloned into pcRII (Invitrogen). The sequences of all inserts showed significant homology with the ETA receptor cDNAs previously cloned in other species. The chick PCR insert was ${ }^{32} \mathrm{P}$-labelled by random priming and used for primary screening of approximately $1 \times 10^{6}$ phages of a chicken fibroblast cDNA library constructed in Uni-Zap XR Vector (Stratagene). Among positive clones, four were screened through two additional rounds and excised using helper phage as pBluescript SK-plasmid. Agarose gel electrophoresis revealed that the clones had inserts of $1.4-3 \mathrm{~kb}$. The 3 $\mathrm{kb}$ clone was sequenced in its entirety on both strands using the dideoxynucleotide sequencing technique and confirmed by automatic sequencing using the Applied Biosystems 377 DNA Sequencer and the dye deoxy-terminator chemistry.

\section{Cloning and sequencing of a partial chicken ETB receptor (cETB)}

Primers $\mathrm{Ab}$ and $\mathrm{Bb}$ were designed on the basis of the previously published partial sequence of the quail ETB receptor (Nataf et al., 1996), i.e. Ab, 5'-GAGATCAAAGAGACCTTCAAG-3' and Bb, 5'TGAGGAGCTGTACTTATTACTGG-3'. cDNA was synthesized from chicken brain RNA and PCR was performed as described above. PCR products of the expected size were TA-subcloned into pcR2.1 (Invitrogen), and sequenced by the dideoxynucleotide sequencing technique. One of the clones was used for in situ hybridization experiments.

\section{Binding and transduction assays}

For transient expression studies of the ETA receptor, the $3 \mathrm{~kb}$ cDNA was subcloned into the NotI and XhoI sites of the expression vector pcDNA3-Zeo (Invitrogen). COS-7 cells were grown in Dulbecco's modified Eagle's medium supplemented with $10 \%$ fetal calf serum, 1 $\mathrm{mM}$ glutamine, 100 units $/ \mathrm{ml}$ penicillin and $100 \mu \mathrm{g} / \mathrm{ml}$ streptomycin at $37^{\circ} \mathrm{C}$ in a humidified $5 \% \mathrm{CO}_{2}$ incubator. Transfections were performed when the monolayer reached $90-95 \%$ of confluence with $15 \mu \mathrm{g}$ of this construct per $75 \mathrm{~cm}^{2}$ flask by the DEAE-dextran method. Transfected cells were immediately seeded in 24-well or 12-well plates for subsequent assays, which were carried out 72 hours after transfection.

${ }^{125}$ I-labelled ET-1 was prepared by chloramine-T iodination and purified by HPLC. Binding assays were performed on intact transfected COS-7 cells 72 hours after transfection in the 24-well plates. Competition binding experiments were carried out for 1 hour at $22^{\circ} \mathrm{C}$ using $0.2 \mathrm{nM}^{125}$ I-ET-1 and increasing concentrations of various ligands: bosentan and Ro46-8443 (from Hoffmann-La Roche) and RU69986 (from Hoechst Marion Roussel). Each experiment was performed at least in duplicate. Binding data were analyzed with a non-linear, least-squares, curve-fitting procedure, Ebda-Ligand (Elsevier-Biosoft, Cambridge, UK).

Inositol phosphate production was measured to determine the functionality of the receptor. As previously described (Torrens et al., 1989), COS cells, subcultured in 12-well plates, were labelled with $2 \mu \mathrm{Ci} / \mathrm{ml}\left[{ }^{3} \mathrm{H}\right]$ myo-inositol for 24 hours. Cells were subsequently incubated with increasing concentrations of ET- 1 at $37^{\circ} \mathrm{C}$ for 30 minutes in the presence of $10 \mathrm{mM} \mathrm{LiCl}$. The total $\left[{ }^{3} \mathrm{H}\right]$ inositol 
phosphate fraction was eluted on a Dowex anion exchange resin $\left(\mathrm{AG}^{\circledR} 1-\mathrm{X} 8\right.$ resin, Bio-Rad) and measured in a scintillation counter.

\section{Chicken embryos}

For all the following studies, approximately 600 white Leghorn chicken eggs were obtained from a commercial farm and incubated at $38^{\circ} \mathrm{C}$ in a humidified atmosphere. Stages are given according to Hamburger and Hamilton (HH) (Hamburger and Hamilton, 1951) or refer to the embryonic day of incubation $(\mathrm{E})$. At the time of dissection, chicken embryos were fixed by $4 \%$ paraformaldehyde in PBS or AFA (5\% acetic acid, $20 \%$ of $4 \%$ paraformaldehyde in PBS, $75 \%$ ethanol), dehydrated and embedded in paraffin for histological analysis or in situ hybridization experiments. Tissue sections $(7 \mu \mathrm{m}$ thick) were mounted on silanated slides. Gross anatomical observations and fine observations of internal malformations were made before or after fixation and dissection. Internal malformations were confirmed both histologically (Hematoxylin/Eosin counterstaining) and after clearing the embryos.

\section{Riboprobe transcription and in situ hybridization}

$\left.{ }^{35} \mathrm{~S}\right] \mathrm{UTP}-$ labelled endothelin receptor riboprobes were synthesized from partial (in pcRII) or full-length (in pBluescript SK-) cETA, and from partial cETB (in pCR2.1), respectively. The in situ hybridization protocol was as previously described (Sibony et al., 1995). Briefly, it comprised a microwave heating pre-treatment to enhance the hybridization signal (12 minutes in a citric acid buffer in a microwave oven) followed by digestion for 20 minutes with Proteinase K. Tissue sections were incubated overnight with $\left[{ }^{35} \mathrm{~S}\right] \mathrm{UTP}$-labelled probe in a humid chamber at $50^{\circ} \mathrm{C}$. Slides were washed in solutions of varying degrees of stringency (from $5 \times \mathrm{SSC}$ with $50 \%$ formamide at $55^{\circ} \mathrm{C}$ to $0.1 \times \mathrm{SSC}$ at room temperature) and digested with RNase A $(20 \mu \mathrm{g} / \mathrm{ml})$ to remove the nonhybridized single-stranded RNA. Macroscopic autoradiography was obtained on Biomax film (Kodak) after 1-3 days, and microscopic autoradiography by dipping the slides in NTB2 liquid emulsion (Kodak). After exposure times from 1 to 8 weeks, slides were developed, fixed and stained with Toluidine Blue before examination under bright or dark field with a Leitz microscope.

\section{Drug administration in ovo}

Eggs were incubated vertically with the air chamber at the top. A small window was opened in the shell and a $30 \mu$ l olive oil drop was introduced onto the shell membrane at 24 (stage HH4-7), 48 (HH11-14), 72 (HH18-21) or 96 (HH23-24) hours of incubation. The oil contained a suspension of the endothelin antagonists at the desired concentration. Control embryos received oil only. The shell opening was sealed with tape and the eggs were returned to the incubator until dissection. Each egg was given a number, which identified it to its treatment group. At the end of the experiment (E9 or E12), the anatomical observation of the embryos was made blind without knowledge of the treatment received by the embryos. Only embryos alive at the time of observation were included in this study.

\section{RESULTS}

\section{Cloning and sequence analysis of the chicken type A endothelin receptor}

PCR primers corresponding to regions of ETA conserved among other species were used to amplify an $837 \mathrm{bp}$ fragment from adult chicken heart cDNA. This PCR fragment was used as a probe for screening a chicken fibroblast cDNA library. A $3 \mathrm{~kb}$ clone was isolated, containing a 1266 nucleotide open reading frame, along with $5^{\prime}$ and $3^{\prime}$ untranslated regions. The northern blot analysis of the chick endothelin type A receptor revealed two transcripts of approximately 2.5 and $3.5 \mathrm{~kb}$, resulting from alternative polyadenylation, splicing or transcription (data not shown).

The deduced protein sequence of the encoded ETA receptor consists of 421 amino acid residues with a calculated molecular mass of approximately $48 \mathrm{kDa}$. The receptor possesses most features common to $\mathrm{G}$ protein-coupled receptors, including a seven-transmembrane domain topology, serine and threonine residues that may be phosphorylated, cysteine residues in the carboxy terminal tail as a putative palmitoylated cluster, and asparagine residues that may be $\mathrm{N}$-glycosylated. The comparison between the cETA receptor and other published ETA receptors is shown in Fig. 1.

\section{Pharmacological characterization of the cETA receptor on COS cells}

Binding of ${ }^{125}$ I-ET-1 to COS-7 cells transfected with the fulllength chick ETA cDNA was specific, saturable and of high affinity $\left(K_{\mathrm{d}}=250 \mathrm{pM}\right.$, data not shown). Competitive binding experiments in these cells showed that this receptor belongs to the type A endothelin receptor family. The cloned cETA receptor displayed ETA selective binding properties to natural and synthetic ligands that were similar to the mammalian ETA receptor. Like the ETA receptors in mammals, the affinity for the chicken ETA was higher for ET-1 and ET-2 than for ET-3 (Table 1). Inositol phosphate stimulation increased in a dosedependant manner with increasing concentrations of ET-1 (effective concentration producing half-maximal response $\left.\left(\mathrm{EC}_{50}\right)=0.2 \mathrm{nM}\right)$, and only weakly with $\mathrm{ET}-3\left(\mathrm{EC}_{50}=5.1 \mathrm{nM}\right)$.

For the in ovo experiments, from among more than a dozen compounds known for their binding properties to the mammalian ET receptors, three synthetic ligands with wellknown and different antagonistic properties in mammals were selected. Their properties were first studied on cETA expressed in COS cells (Table 1). RU69986, an ETA specific antagonist, and bosentan (Ro47-0203), a mixed type of antagonist, were chosen to work in vivo because of their high affinity for the cETA receptor and their effect on ET-1-induced inositol

Table 1. Pharmacological characterization of the chicken ETA receptor

\begin{tabular}{|c|c|c|c|c|c|c|}
\hline & \multicolumn{6}{|c|}{$K_{\mathrm{i}}(\mathrm{nM})$} \\
\hline & \multicolumn{3}{|c|}{ Endogenous ligands } & \multicolumn{3}{|c|}{ Antagonists } \\
\hline & ET-1 & ET-2 & ET-3 & RU69986 & Bosentan & Ro46-8443 \\
\hline Chicken ETA* & 0.8 & 1.3 & 311 & 1.7 & 5.2 & 116 \\
\hline Mammalian ETA** & 0.9 & 7.2 & 900 & 1.3 & 4.7 & 1100 \\
\hline
\end{tabular}

*Data obtained by competition of ${ }^{125}$ I-labelled ET-1 binding with various compounds in COS-7 cells expressing cETA.

**Data published by Arai et al. (1990) for the ETs; Clozel et al. (1994) for bosentan; Breu et al. (1996) for Ro46-8443 and personal communication (J. P. Vevert) for RU69986. 
phosphate production. At $10^{-6} \mathrm{M}, \mathrm{EC}_{50}$ of the ET-1 was shifted from 0.2 to $5.7 \mathrm{nM}$ with RU69986 and $4.4 \mathrm{nM}$ with bosentan. In contrast, the mammalian ETB-specific antagonist Ro468443 has a very low affinity for the cloned cETA receptor (Table 1) and, consequently, does not significantly decrease the inositol phosphate production. It was therefore chosen as a negative control.

\section{Distribution of endothelin receptors in the chick embryo}

We have studied the mRNA expression pattern of both the chick ETA and ETB receptors from $\mathrm{E} 1$ to $\mathrm{E} 5$, particularly focusing on neural and cardiac lineages (Fig. 2).

From HH8 to HH18, no expression of the type A receptor was detected in the embryo (Fig. 2B), whereas in the same embryos the ETB receptor appeared in the NC cells as soon as they emigrate from the neural tube (NT) (Fig. 2C). ETA mRNA-positive cells appeared first in branchial arches around $\mathrm{E} 3$, and the in situ hybridization signal was located in the mesectodermal cells surrounding the arteries and was absent in the aortic arch endothelium (Fig. 2D-F), in a mirror image to ETB mRNA (Fig. 2G). There was also no ETA hybridization signal in the epithelium of the branchial arches (Fig. 2E,F).

In the developing heart (Fig. 2H-J), the two receptor types were also expressed in different tissues: ETA was confined to the myocardium (Fig. 2I) and ETB was restricted to the endocardium (Fig. 2J). Whereas ETB was very strongly expressed in neural structures such as dorsal root ganglia or sympathetic ganglia, ETA was confined in the cephalic region to the wall of the perineural vasculature but was not detected in the neuroepithelium itself (Fig. $2 \mathrm{~K})$.

In most other organs, ETB was confined essentially within neural structures and the endothelium. ETA had a more diffuse distribution, mostly in the mesodermal components of various organs such as the bronchi (Fig. 2L,M), pharyngeal digestive tube and anterior gut, and also mesonephros (data not shown).

\section{Phenotype of the embryos submitted to endothelin antagonists}

In embryos treated with RU69986 or bosentan (pure ETA or ETA/ETB antagonists, respectively) at E2 and observed at E9 or E12, the first apparent features were a partial or complete absence of lower beak, occasionally associated with less conspicuous malformations of the upper beak. The malformations of the package. mandible components of the beak in treated embryos ranged from the total absence of mandible to a shorter and slighltly crooked lower beak (Fig. 3A-C)), with a stunted or missing tongue and a thicker and shortened neck. The shape of the opening of the otic vesicle also appeared modified by the

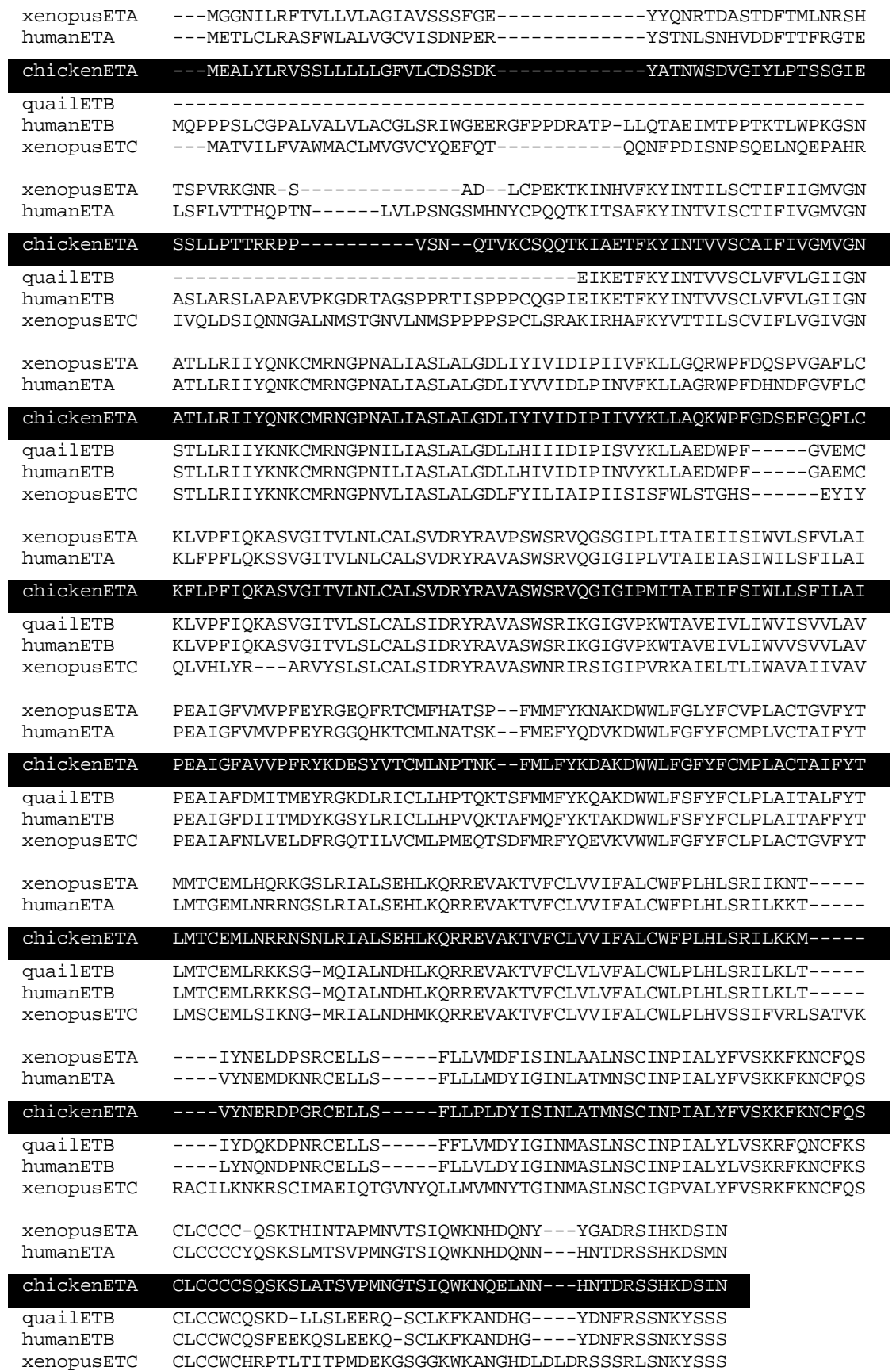

Fig. 1. Sequence comparaison of cETA with other ET receptors. The chicken ETA receptor displays $76 \%$ identity with human ETA (Elshourbagy et al., 1993), 70\% with Xenopus ETA (Kumar et al., 1994), 65\% with partial quail ETB (Nataf et al., 1996) 64\% identity with human ETB (Sakamoto et al., 1991) and 51\% with Xenopus ETC receptor (Karne et al., 1993). The cETA sequence has been deposited in the GenBank Data Library under accession number AF040634. The respective accession numbers of the other sequences are L06622 (hETA), U06633 (xETA), X99295 (qETB), S44866 (hETB) and L20299 (xETC). Sequences were aligned using ClustalW from the Wisconsin GCG 
treatment with a widening of its hole (data not shown). These external malformations were used to evaluate the result of the treatment. It is noteworthy that the mortality rate was similar in control and treated embryos and that, in all groups, most of the embryos died before or on the day of treatment. Taking into account all the apparent anomalies of the head, the penetrance of the defects reached $70 \%$ in RU69986- or bosentan-treated embryos surviving at E12 (Table 2). With oil-, Ro468443 (an ETB-specific antagonist)- or Sar-Ile ${ }^{8}$ AngII (angiotensin receptor antagonist)treated embryos, none of the anatomical features ascribed to bosentan or RU69986 were observed (Table 2). This clearly demonstrated that the observed phenotypes were due to the specific blockade of the ETA receptor and not to ETB or any other unrelated receptor.

The external phenotype of each treated embryo was followed by the examination of internal structures after specific staining and clearing of the embryos (Fig. 3D-F), permitting the precise identification of which hypobranchial skeletal elements were missing, deformed or reduced in size in the treated embryos. Compared to control embryos, no malformations were detected in axial or limb skeleton, except for an accentuated curvature of the cervical part of the spinal column, probably due to mispatterning of neck muscles, which produced a thickening and shortening of the neck (data not shown). In the lower jaw, both Meckel's cartilage and its associated covering dermal bones were absent in the most affected embryos (Fig. 3F), which were the majority of treated embryos. Indeed, these structures appeared as small dots at the site where they normally bud to build part of the mandible skeleton. In the less affected embryos (Figs 3E, 4A), the Meckel's cartilage as well as the dermal bones (angular, surangular, opercular or dentary) were present but dramatically reduced in length. Among components of the head internal skeleton, the hyoid apparatus was subject to severe deformations and size reduction up to a complete lack of some of its components (Figs 3E,F, 4B). The epibranchial cartilage was never observed after treatment, whereas the basibranchial, ceratobranchial, basihyal and the entoglossum cartilages presented various degrees of gross dysmorphogenesis such as widening or flattening, and they never lay in the same plane as in control embryos (Fig. 4B). Moreover, two additionnal cartilaginous structures developed occasionally from the rostral part of the ceratobranchial in treated
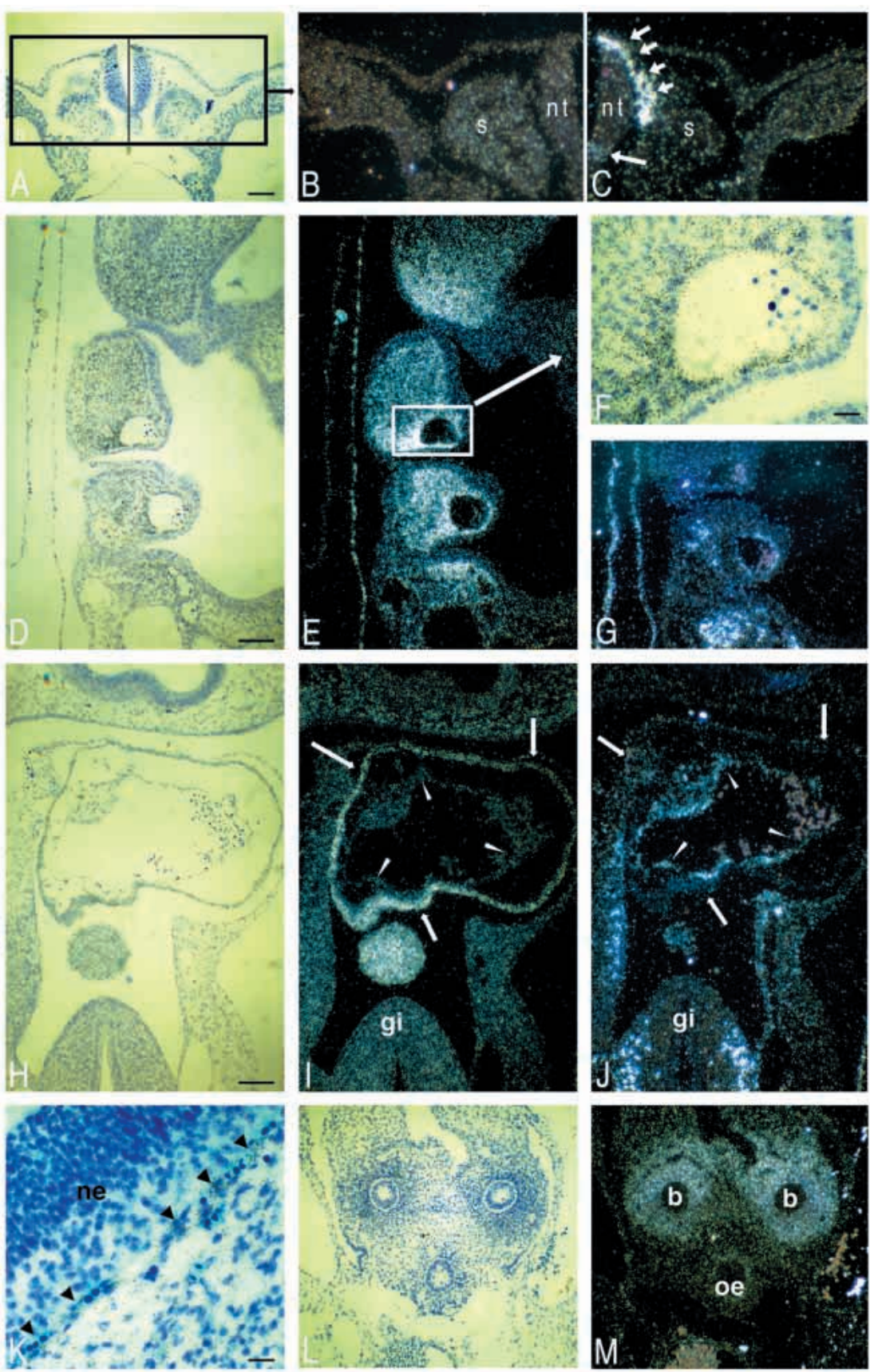

Fig. 2. In situ hybridization analysis of cETA and cETB expression. (A-C) E2.5; B and $\mathrm{C}$ are enlarged views of the boxed area in A. ETA is not detectable (B). ETB is mostly expressed in the neural crest cells emigrating along the medioventral pathway (short arrows in $\mathrm{C}$ ); a weak signal is also observed in the floor plate (long arrow in C). At E3 (D-J), ETA (D-F and H,I) and ETB (G,J) are expressed in the branchial arches and the heart. ETA mRNA is expressed only in the mesenchyme of the branchial arches (D-F), whereas ETB mRNA is detected in the endothelium of the aortic arches $(\mathrm{G})$. Neither ETA nor ETB are expressed in the ectodermal or endodermal epithelia of the arches (D-G). In the heart (H-J), myocardium (I,J, arrows) expresses ETA receptor mRNA (I) and endocardium (I,J, arrowheads) ETB mRNA (J). The enteric ganglia, which derive from the vagal neural crest cells, are ETA negative (I), but are strongly ETB-positive (J). At E5, the wall of the capillaries (arrowheads) lining the outer aspect of the neuroepithelium (itself ETAnegative) expresses ETA mRNA (K, arrowheads). (L,M) Mesenchymal cells of the main bronchi are positive for ETA (M). b, bronchi; gi, gastrointestinal tract; ne, neuroepithelium; nt, neural tube; oe, oesophagus, s, somite. Bars, $100 \mu \mathrm{m}$ (except for $\mathrm{F}$ and $\mathrm{G}, 20 \mu \mathrm{m}$ ). 
Fig. 3. Effects of endothelin antagonist treatment on the craniofacial development of the chick embryo. (A-C) External appareance of the head of a control (A) and of two RU69986-treated embryos, partially (B) or fully (C) affected. Alcian Blue and Alizarin Red skeletal preparation of embryos (D,E,F) correspond, respectively, to $(\mathrm{A}, \mathrm{B}, \mathrm{C})$. The Meckel's cartilage (white arrow) is reduced or absent and the hyoid bone is severely affected (black arrowhead) in the treated embryos $(\mathrm{E}, \mathrm{F})$.
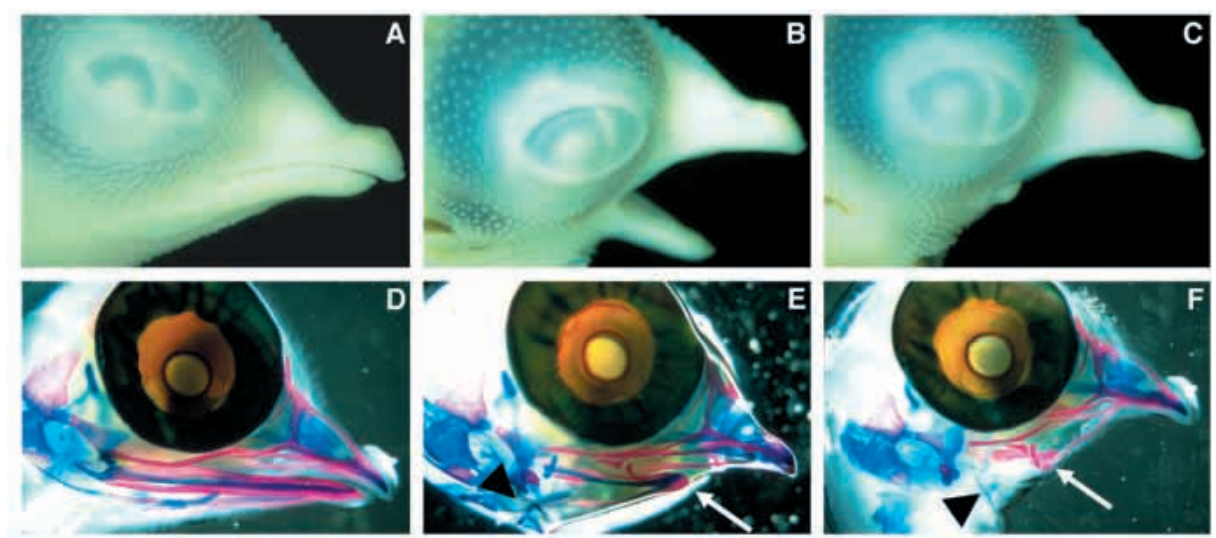

embryos and not in controls (Fig. 4B). Specific staining of cartilages and bones revealed that in absence of external malformations ( $30 \%$ of the treated embryos), most embryos still displayed a dysmorphogenesis of the hyoid apparatus that was quite similar to that described above for the most affected embryos.

The dissection of the neck and thoracic region revealed that in most of the treated embryos the thyroid is hypoplastic on one or both sides. Likewise, the development of the thymus is affected by the treatment (data not shown).

The heart and its associated vasculature were examined anatomically (Fig. 5A) and histologically at E9 or E12 in both control and RU69986 (Fig. 5B,C) or bosentan-treated (not shown) embryos. A wide range of cardiovascular malformations was recorded. There was no commonly observed pattern of defects, with the exception of a ventricular septum defect often associated with a persistent truncus arteriosus (Fig. 5B,C). Various abnormalities of outflow tract including aorta, carotids and subclavian arteries were apparent such as the loss of an artery or, conversely, one or several additional vessels or abnormal bifurcations in the great vessels of the thoracic region. When observed at E4 (2 days after treatment), the aortic arch arteries, which give rise to the great vessels of the outflow tract, appeared normal in size and shape

Table 2. Summary of morphological defects

\begin{tabular}{|c|c|c|c|c|}
\hline \multicolumn{3}{|c|}{ Treatment } & \multirow{2}{*}{\multicolumn{2}{|c|}{$\begin{array}{l}\text { Skeletal morphological } \\
\text { defects in live embryos }\end{array}$}} \\
\hline \multirow[b]{2}{*}{ Drug } & \multirow{2}{*}{$\begin{array}{l}\text { Embryos } \\
\text { (death) }\end{array}$} & \multirow[b]{2}{*}{ Dose } & & \\
\hline & & & Embryos & $\%$ \\
\hline Vehicle & $10(2)$ & None & 0 & 0 \\
\hline $\begin{array}{l}\text { RU69986 } \\
\text { (ETA antagonist) }\end{array}$ & $15(2)$ & $5 \mathrm{mg} / \mathrm{ml}$ & 8 & 62 \\
\hline $\begin{array}{l}\text { Bosentan } \\
\quad \text { (mixed antagonist) }\end{array}$ & $16(4)$ & $5 \mathrm{mg} / \mathrm{ml}$ & 8 & 67 \\
\hline $\begin{array}{l}\text { Ro46-8443 } \\
\text { (ETB antagonist) }\end{array}$ & $16(5)$ & $5 \mathrm{mg} / \mathrm{ml}$ & 0 & 0 \\
\hline $\begin{array}{c}\text { Sar-Ile }{ }^{8} \text { AngII } \\
\text { (angiotensin } \\
\text { antagonist) }\end{array}$ & $10(2)$ & $5 \mathrm{mg} / \mathrm{ml}$ & 0 & 0 \\
\hline
\end{tabular}

These data are representative of a typical experiment performed at E2 of incubation and observed at E12. There is no significant difference in the extent of mortality between embryos treated with vehicle or drug. Only the live embryos were further investigated for internal morphological and/or histological analysis. in treated embryos compared to control embryos. In addition, we looked at the distribution of the smooth muscle $\alpha$-actin at the same age. The immunostaining for this marker was quite similar in both control and treated embryos (Fig. 5D,E).

\section{Dose and time-dependency of the phenotype}

Beside being antagonist specific, the phenotype described above also depended on the dose and the time of ETA antagonist administration.

To further validate the in ovo pharmacological inactivation of the ETA receptor, we performed a dose-response curve (Fig. $6 \mathrm{~A})$. The penetrance of the phenotype in embryos treated with ETA-specific antagonists was enhanced with increasing concentrations of the drug from 0 to $10 \mathrm{mg} / \mathrm{ml}$, reaching a plateau at a dose of $5 \mathrm{mg} / \mathrm{ml}$. The highest dose of $10 \mathrm{mg} / \mathrm{ml}$ did not increase the penetrance in living embryos $(68 \pm 4 \%)$ compared to embryos treated with $5 \mathrm{mg} / \mathrm{ml}(70 \pm 8 \%)$, but rather tended to be lethal. This lethality can be explained by toxicicity of the higher doses, but the possibility of an aggravated phenotype, ultimately leading to embryonic death, cannot be ruled out.
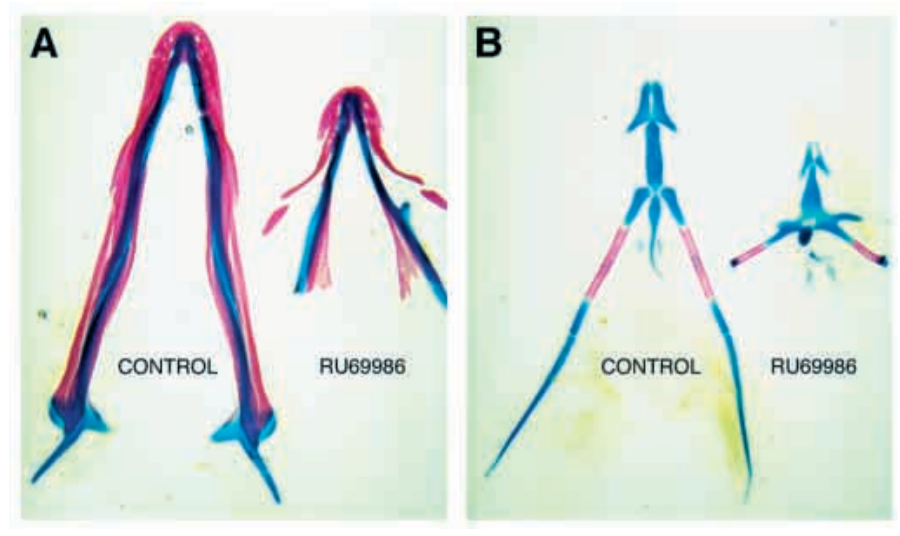

Fig. 4. Morphological aspect of the hypobranchial skeleton of control (left) and RU69986-treated embryos (right). The lower jaw and the hyoid apparatus were dissected from E12 control or treated embryos. (A) Whereas the cartilage and bone elements of the mandible of the control embryo (left) are completely normal, the Meckel's cartilage of the treated embryo (right) is greatly reduced and covered by strongly deformed or absent dermal bones.

(B) Compared to the control (left), the hyoid apparatus is highly abnormal and curved as a result of the RU69986 treatment (right). 

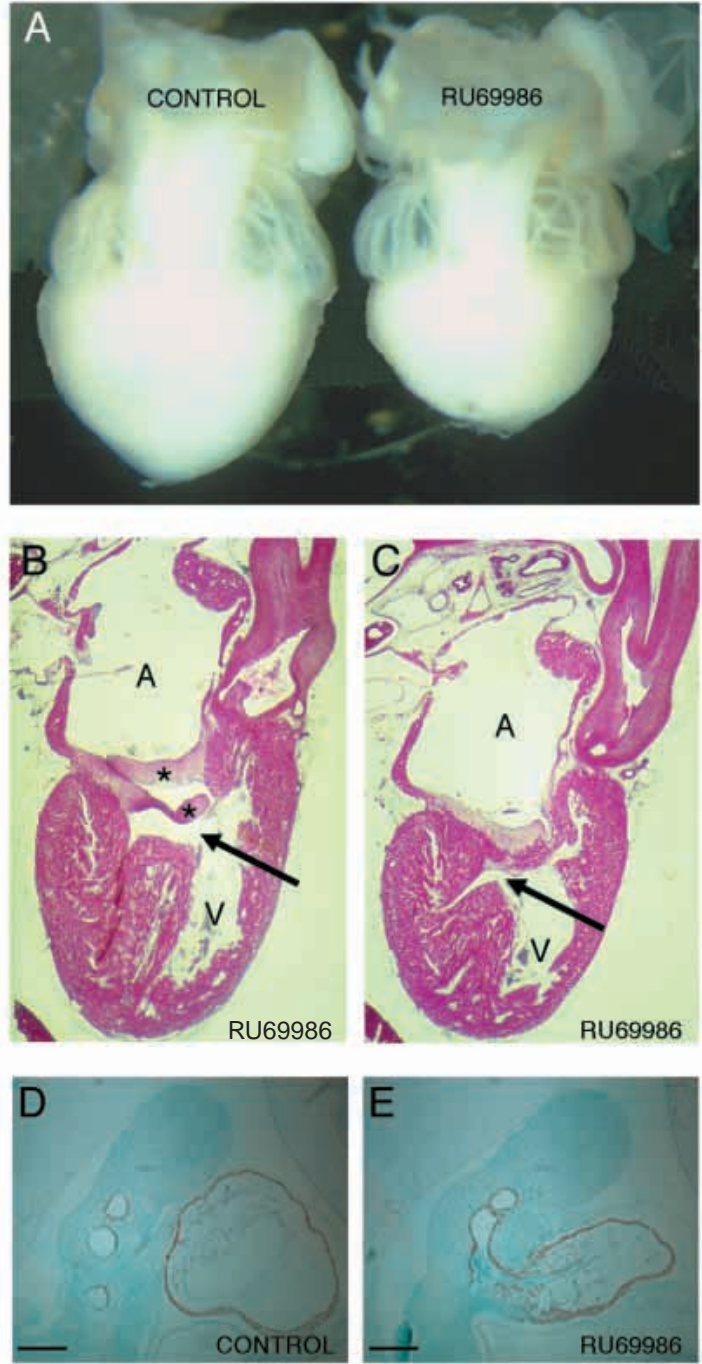

Fig. 5. Cardiovascular defects. (A) Gross anatomy at E12 of the heart of a control embryo (left) and a RU69986-treated embryo (right). The ventricles are smaller in the treated embryo, in contrast to the auricles, which look distended. (B,C) Histological analysis of a heart of a RU69986-treated embryo. A ventricular septum defect (arrow) is visible and also an abnormally dilated atrium. Note also the lack of septation between the aorta and the pulmonary arteries. The two asterisks in B mark on the valvule two thickened and abnormally long leaflets. (D,E) Alpha-actin immunostaining of smooth muscles. Used as a marker of vessel wall differentiation, at E4 $\alpha$-actin has (sagittal sections) a similar expression pattern in aortic arch arteries of both control (D) and RU69986 (E) embryos. A, atrium; V, ventricle. Bars, $200 \mu \mathrm{m}$.

In order to determine the most sensitive developmental stage(s) to the antagonist treatment, we undertook a time-frame experiment (Fig. 6B). We administered a single dose $(5 \mathrm{mg} / \mathrm{ml})$ of ETA antagonist at different development ages (from 24 to 96 hours of incubation). At E2 (48 hours of incubation), the treatment induced the maximum percentage $(70 \pm 8 \%)$ of defects in the craniofacial structures of the embryos and also the most severe malformations. At this stage, almost all embryos had a complete regression of the lower beak. The phenotype observed after treatment at 24 or 72 hours of
A

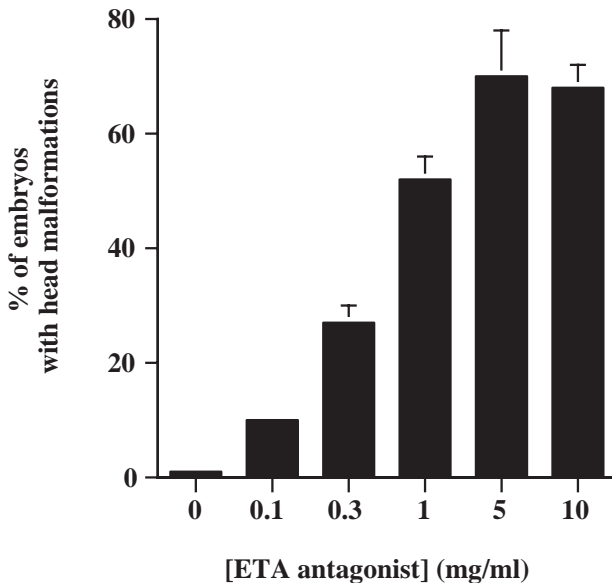

B

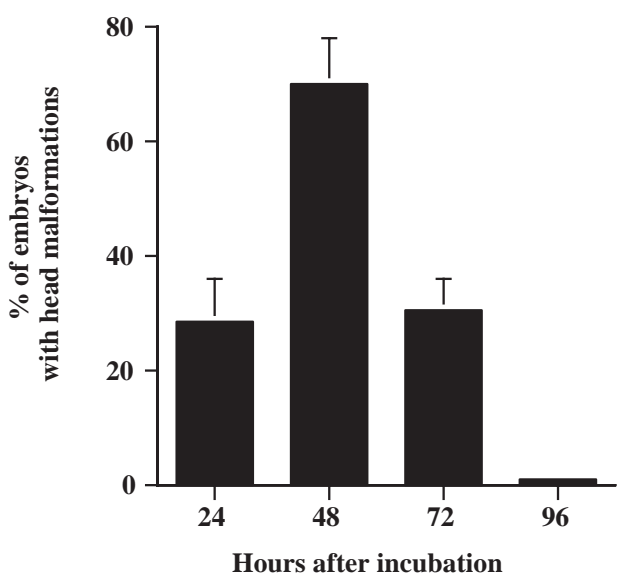

Fig. 6. Characterization of a dose- and time-dependent effect of the antagonist treatment. (A) Percentage of malformations after treatment of embryos by $0,0.1,0.3,1,5$ or $10 \mathrm{mg} / \mathrm{ml}$ of bosentan in suspension in a $30 \mu \mathrm{l}$ oil drop. (B) Percentage of malformations according to the time of treatment by $5 \mathrm{mg} / \mathrm{ml}$ of RU69986 or bosentan $(24,48,72$ or 96 hours of incubation). For A and B, the malformations observed are those described in detail in the Results and are based on the external apparence of the beak of the embryos at E9 or E12. Values represent mean \pm s.e.m. of two or three independent experiments.

incubation was much less severe and penetrant $(28 \pm 7 \%$ and $30 \pm 5 \%$, respectively). None of the embryos treated at 96 hours were affected by the treatment. To summarize, the frequency of craniofacial malformations increased from $28 \%$ to $70 \%$ and then decreased to $0 \%$ for a treatment beginning at $24,48,72$ or 96 hours of incubation. In keeping with the rise and drop in percentage of affected embryos, there was a tendency for an increased and then a diminished severity of the malformations observed.

These results confirm the specificity of the malformations induced by the blockade of the ETA receptor. More importantly, they show that there is a narrow time window that is critical for achieving a normal development and patterning of the neural crest-derived structures in branchial arches, which depend on the ET-1/ETA pathway. 


\section{DISCUSSION}

One of the most powerful, useful and elegant means of determining the function of a gene of interest is the technique of gene disruption by homologous recombination. Nevertheless, because it is time and labour consuming, irreversible and restricted to the mouse, other approaches have been developed in other species, in vivo or ex vivo, such as gene inactivation by antisense oligonucleotide, or gene product inhibition by administration of drugs. In the well-studied chicken embryo model, commonly used techniques are the local implantation of beads soaked with products of interest, the transfection of retrovirus overexpressing genes of interest or the treatment of the whole embryo in culture.

\section{Validation of the experimental model}

Since the main aim of our study was to inactivate the product of the ETA gene in ovo and within the whole embryo, we designed a pharmacological blockade of this receptor by administration of antagonists using a simple and non-toxic route. The endothelin system was particularly suited to this approach, because of both its involvement in early development and the existence of various available selective antagonists. However, such a study required the following important preconditions: (1) molecular cloning of the receptor; (2) pharmacological studies to select antagonists with high affinity, selectivity, biodisponibility and slow metabolism; and (3) determination of the expression pattern of the receptor during embryonic development. These prerequisites for exploring the similarity of the avian endothelin system with that of the mammals appeared necessary in view of the nonsystematic conservation between these two classes of vertebrates.

Indeed, the endothelin type A receptor is conserved between birds and mammals, since the complete sequence of the cETA receptor that we report displays a high identity with the sequence of the mammalian endothelin ETA receptors. In addition, the pharmacological assays reported here clearly demonstrate that the binding parameters and the antagonist properties of the ligands used in this study are conserved between avian and mammalian ETA receptors, whereas avian chicken angiotensin II (Kempf et al., 1996) and bradykinin (Schroeder et al., 1997) receptors, for instance, behave differently towards mammalian antagonists. In order to determine the optimal period of treatment to inactivate the ETA receptor with antagonists at an early stage of development, we established the spatio-temporal expression pattern of the endothelin receptors. At the earliest stage studied, NC cells that emigrate from the NT have already become ETB-positive, whereas they are still ETA-negative along both the dorsolateral and medioventral pathways of migration. Compared to the human (Brand et al., 1998) and mouse embryos (Clouthier et al., 1998), the ETA mRNA expression is delayed in the chick embryo: in the mammalian embryo both ETA and ETB appear almost simultaneously in early migrating $\mathrm{NC}$ cells (and possibly in the same cells in human), whereas in the chick embryo, ETA receptor is detected only after NC cells of mesectodermal lineage have reached the branchial arches. In contrast, ETB expression is detected in cells as early as stage HH8 when they emigrate from the NT, an observation that has already been reported in quail (Nataf et al., 1996). Thus, before the invasion of the branchial arches, $\mathrm{NC}$ cells express only ETB receptor mRNA, and no ETA. It is only at E3, at the time of colonization of the branchial arches by the cranial NC cells, that these cells split into two lineages that react differently to the anti-HNK1 antibody (Le Douarin et al., 1992). Neural type cells, HNK1 positive, remain ETB positive and mesectodermal cells, HNK1 negative, become ETA positive (our unpublished observation).

These data have allowed us to select several non-peptidic antagonists that have been applied at stages of cETA expression to pharmacologically inactivate the ETA pathway in the chick embryo. This strategy is efficient, reproducible and selective and permits the production of a large number of individuals displaying a characteristic phenotype.

\section{Similar phenotype obtained by pharmacological blockade of the chicken ETA receptor and inactivation of ET-1 or ETA genes in mice}

ETA receptor inactivation as operated here by an antagonist ligand produces a phenotype comparable to that of ET-1 (Kurihara et al., 1994, 1995a,b) or ETA (Clouthier et al., 1998) null mice. However, it is worth noting that a very high incidence of malformations is obtained with a single injection of antagonist in the chick embryo, whereas the ET-1 gene inactivation in mice required the continuous administration of anti-ET-1 antibody or a selective ETA receptor antagonist in pregnant mice to reach a high degree of malformation (Kurihara et al., 1995a). In the present study, the administration of an ETA-specific antagonist (RU69986) or an ETA/ETB antagonist (bosentan) induced all the anomalies observed, which did not appear after the administration of a mammalian ETB antagonist (Ro46-8443) or an endothelin-unrelated antagonist (Sar-Ile ${ }^{8}$ AngII). It is most likely that the phenotype is not due to toxicity because of (1) the total similarity of malformations obtained after ETA blockade in chick and ETA inactivation in mice, and the absence of the same malformations with non-specific or unrelated antagonists; (2) the use of ETA antagonists with distinct chemical structures (bosentan and RU69986), which yield the same phenotype; (3) the inability of bosentan to bind to 40 other receptors (Clozel et al., 1994). In addition, the dose-response effects and the time-frame experiments confirmed the validity and efficacy of pharmacological treatment for this purpose. All the previous data are in favor of a direct effect of the antagonists via the ETA receptor, although we cannot exclude the possibility of an indirect effect via undetermined pathways.

Since the phenotypes obtained after inactivation of ETA by a specific antagonist in the chicken and by ET-1 or ETA gene inactivation in the mouse appear identical, we can conclude that, in all cases, the ET-1/ETA pathway is involved. Most of the defects are observed in tissues or organs derived from the branchial arches and, more precisely, from the ectomesenchyme of all branchial arches. Thus, the disrupted development of the first (mandibular) and second (hyoid) arches results in abnormalities in the hypobranchial skeletal elements. The functional blockade of the ETA receptor by antagonist treatment in this study or inactivations of the ET-1 (Kurihara et al., 1994) or ETA (Clouthier et al., 1998) genes in the mouse studies suppressed the stimulus responsible for the differentiation and/or proliferation of the cephalic NC cells within the branchial arches. The hyoid apparatus is affected in 
almost all treated embryos, while the antagonist treatment has a smaller impact on the ectomesenchymal cells of the mandibular arch, which contribute to the Meckel's cartilage and membrane bones of the lower jaw. The wider the origin of the ectomesenchyme, the more severe the defects after treatment. Indeed, the hyoid bone derives from all the rhombomeres and the posterior mesencephalon, whereas only the posterior half of the mesencephalon and rhombomeres 1, 2 and 3 (partly) contribute to the mandible (Lumsden et al., 1991; Couly et al., 1996).

Organ defects resulting from ETA receptor blockade in the other arches were also observed with a cumulative penetrance of almost $100 \%$. The heart and its associated vasculature are very often affected with variable and heterogeneous phenotypes (ventricular septum defect, no outflow septation, missing or surnumerary vessels) which, here again, is consistent with the results obtained by gene inactivation of ET1 (Kurihara et al., 1995a) and ETA (Clouthier et al., 1998). Moreover, in our experimental model, most of the treated embryos have abnormal thyroid and thymus, as also reported in mutant mice (Kurihara et al., 1995b). The pharyngeal arch patterning is similarly (partly or totally) disrupted by inactivation of numerous genes such as, for instance, Hox-1.5 (Chisaka and Capecchi, 1991), MFH-1 (Iida et al., 1997), RARs (Lohnes et al., 1994) or also teratogenic administration of retinoic acid (Richman, 1992). These results demonstrate that all these genes are not only expressed but the gene products are functional and essential for the participation of pharyngeal derivatives of NC cells to the organogenesis of all these organs and structures. All these mispatternings were also previously obtained by ablation of the cardiac NC cells, which migrate to the third, fourth and sixth pharyngeal arches (Kirby and Waldo, 1995).

Because the gene inactivation is total from the beginning of embryonic development, this method does not reveal anything about the temporal window of sensitivity to ET-1 signal of the branchial ectomesenchyme. The pharmacological 'knock down' is more versatile and allows gene product inactivation for limited periods of time. We reasoned that the delay between E2, when the embryos were treated with the antagonists, and E3, when the mesectodermal cells of the branchial arches express ETA receptor, allows for the diffusion of the antagonist suspension from the oil to the target cells and the functional inactivation of the receptor. In fact, this is confirmed by the low incidence of malformations observed in embryos treated at 24 hours of incubation. This lower incidence can be explained by the extended delay ( 48 hours) between the treatment and the period of sensitivity at the stage of colonisation of the branchial arches, a delay during which extensive diffusion in the whole egg and metabolism of the active compound can occur. Conversely, treatment at or later than 72 hours of incubation may be too late for the antagonist to reach the target cells at a time when they are still fully sensitive to ET-1. Therefore, we can conclude that the mesectodermal cells of the branchial arches have a very limited period of sensitivity to endothelin, between E3 and E4, the same period during which the branchial arch epithelium expresses the corresponding ligand ET-1 (Nataf et al., 1998).

\section{Cellular deficiency in the branchial arches}

A major question is to know whether ET-1 via its ETA receptor acts on NC cells by altering their migration, proliferation and/or differentiation. The recent studies of gene inactivation of ET-1, ETA or ECE-1 (Kurihara et al., 1994, 1995a; Clouthier et al., 1998; H. Yanagisawa et al., 1998a) failed to solve this question. The present pharmacological blockade of the ETA receptor could not fully clarify this problem either. However, our study not only rules out the effect of the endothelin system on migratory $\mathrm{NC}$ cells, but also shows the time dependance of the endothelin effect. Indeed, in this study, we show the existence of a critical, narrow and specific temporal window (between E3 and E4) for the ETA-dependent craniofacial organogenesis and arch remodelling. Before the beginning of this sensitive period, both the absence of the ETA receptor in migrating NC (and adjacent) cells in the chick embryo and the appearance of this receptor around E3, when the cells have reached the branchial arches, rule out a role of the ET-1/ETA pathway on the migration of the NC cells. Surprisingly, the insensivity of the migration process to ET-1/ETA pathway has also been shown recently in mice, despite the presence of ETA receptor in migrating NC cells in mouse embryo (Yanagisawa et al., 1998c). Since NC cells migrate normally to the branchial arches, ETA may be crucial only in postmigratory NC cells after they colonize the branchial arches. Epitheliomesenchymal interactions would be impaired by either the absence of ET-1 production from the branchial arch epithelium (Kurihara et al., 1995a), or the absence (Clouthier et al., 1998) or the blockade (this study) of the ETA receptor in ectomesenchyme. Preliminary attempts at comparing control and antagonist treated embryos at E4 (2 days after treatment) indicate that neither the hybridization signal for the cETA receptor mRNA (our unpublished observation), nor the expression of $\alpha$-actin, taken in this study as one among many possible functional markers of differentiation, are modified by the treatment at this stage. This last observation may suggest that the early alteration of the NC cells (between E3 and E4) only has repercussions on a later process of arch remodelling, as previously proposed after ablation of cardiac NC cells (Waldo et al., 1996).

Clearly, if the migration process can be ruled out, the fundamental question of proliferative versus differentiating roles of the ET-1/ETA system will require much more extensive and precisely targeted studies, as already discussed in the ETA gene inactivation studies (Clouthier et al., 1998; H. Yanagisawa et al., 1998b). Furthermore, unravelling the order of events downstream of the ETA stimulation remains a major challenge. For example, further studies are necessary to determine whether the effects of ET-1 via ETA are restricted to ectomesenchymal cells (ETA positive) of the branchial arches or, alternatively, if they extend through and beyond these last ones to neighbouring cells (ETA negative) to convey information that will direct their fate.

\section{Functionality of the ETA and ETB receptors in development}

The treatment of embryos with a selective antagonist to ETA (RU69986) or with a mixed antagonist to ETA and ETB (bosentan) generates the same anatomical and histological defects and at equal dose, with approximately the same penetrance of the phenotype. Nevertheless, since bosentan binds to ETB receptor on chicken membrane preparations (our unpublished observation), one might have expected a larger 
range of defects after bosentan treatment corresponding to the blockade of the ETB receptor, which is essential to the development of the myenteric ganglia and epidermal melanocytes. However, neither the gene inactivation of ETB (Hosoda et al., 1994) nor ET-3 (Baynash et al., 1994) in mouse, nor bosentan treatment in chicken embryo at early stages, induced obvious defects in other ETB-positive neural structures such as dorsal root or sympathetic ganglia. Likewise, in ET-1-/- mice, no apparent anomalies were observed in neural tissues, although they expressed ETB receptor mRNA very early in development and ET-1 can bind ETB with high affinity. This apparent lack of effect of ETB blockade suggest that the ET-1-ET-3/ETB pathway may not be functional at these early stages of development, in spite of the abundance of ETB mRNA expression. The same question arises as to the functionality of the ETA receptor in the NC cells migrating from the NT to the branchial arches: whether these cells express ETA, as in mammals, or not, as in chick, they do not seem to be ET-1 responsive until the time they colonize the branchial arches. Further studies are needed to explain the apparent lack of function of both receptor signaling in these neural-crest derivatives.

\section{Conclusion}

In this study, we demonstrate the usefulness of pharmacological inactivation by using specific antagonists as a simple, rapid, powerful and easily adaptable method of 'conditional' gene product inactivation in the chick embryo. The vehicle used to deliver the active compound, oil, is chemically neutral, non-toxic and hydrophobic. Chemical neutrality means that most compounds within a wide range of molecular mass should be rather stable until they are released in the egg and reach their target sites. Owing to the hydrophobicity of the oil, the active compounds, particularly polar molecules, are in suspension and released very slowly to the external medium, thus ensuring prolonged and constant effects rather than a single surge followed rapidly by very low levels in the case of the usual hydrophilic routes of administration.

The experimental model presented in this study can be as easily applied from day 0 of incubation up to the terminal stages of differentiation. The treatment can be limited to a single injection and targeted to temporally defined population of cells, or repeated several times to widen its temporal range of effects. The coadministration, simultaneously or successively, of compounds blocking or suractivating different systems will allow the unravelling of the combinatorial balance of these various influences. In addition, because of the large number of embryos that can be obtained, the expression of many genes influenced by the treatment might be easily investigated.

On the one hand, with this convenient model, we confirm that the ET-1/ETA pathway is critical in the early embryo of vertebrates, since the phenotype is identical between chick and mouse. On the other hand, we have delineated the role of this pathway in normal development to a narrow and specific temporal window, although we are as yet unable to dissect the cellular basis of the action of ET-1/ETA in the branchial arches.

It will be of particular interest to focus on putative genes downstream of the ETA activation such as Hand genes (Srivastava et al., 1997; Firulli et al., 1998) or MFH-1 (Iida et al., 1997). In other words, attention should now turn to genes whose inactivation produce phenotypes close or similar to that of the ETA inactivation. As previously pointed out for retinoid involvement in development (Dickman et al., 1997), a variety of approaches and models will be required to dissect the underlying mechanisms of morphogenesis. Both the gene inactivation, where the gene is knocked out throughout the development, and the pharmacological blockade, where the product is temporarily 'knocked down' as used in the present study, will help to clarify the interactions among growth factors such as endothelins, protein kinase and transcription factors in regulating gene expression and cell differentiation during normal and abnormal embryonic development.

This work is dedicated to the memory of Etienne Wolff (19041996), a great embryologist and teratologist who inspired this study.

The authors thank M. T. Morin and F. Mongiat for excellent technical assistance. We are particularly grateful to Hoechst Marion Roussel for the gift of RU69986 and radiolabelled ET-1, and to Martine Clozel (Hoffmann-La Roche) for providing us with a generous supply of Bosentan and Ro46-8443.

\section{REFERENCES}

Arai, H., Hori, S., Aramori, I., Ohkubo, H. and Nakanishi, S. (1990). Cloning and expression of a cDNA encoding an endothelin receptor. Nature 348, 730-732

Baynash, A. G., Hosoda, K., Giaid, A., Richardson, J. A., Emoto, N., Hammer, R. E. and Yanagisawa, M. (1994). Interaction of endothelin-3 with endothelin-B receptor is essential for development of epidermal melanocytes and enteric neurons. Cell 79, 1277-1285.

Brand, M., le Moullec, J. M., Corvol, P. and Gasc, J. M. (1998). Ontogeny of endothelins-1 and -3, their receptors and endothelin converting enzyme1 in the early human embryo. J. Clin. Invest. 101, 549-559.

Breu, V., Clozel, M., Burri, K., Hirth, G., Neidhart, W. and Ramuz, H. (1996). In vitro characterization of Ro 46-8443, the first non-peptide antagonist selective for the endothelin ETB receptor. FEBS Lett. 383, 37-41

Chisaka, O. and Capecchi, M. R. (1991). Regionally restricted developmental defects resulting from targeted disruption of the mouse homeobox gene hox-1.5. Nature 350, 473-479.

Clouthier, D. E., Hosoda, K., Richardson, J. A., Williams, S. C., Yanagisawa, H., Kuwaki, T., Kumada, M., Hammer, R. E. and Yanagisawa, M. (1998). Cranial and cardiac neural crest defects in endothelin-A receptor-deficient mice. Development 125, 813-824

Clozel, M., Breu, V., Gray, G. A., Kalina, B., Loffler, B. M., Burri, K., Cassal, J. M., Hirth, G., Muller, M., Neidhart, W. and Ramuz, H. (1994). Pharmacological characterization of bosentan, a new potent orally active nonpeptide endothelin receptor antagonist. J. Pharmacol. Exp. Ther. 270, 228-235.

Couly, G., Grapin-Botton, A., Coltey, P. and Le Douarin, N. M. (1996). The regeneration of the cephalic neural crest, a problem revisited: the regenerating cells originate from the contralateral or from the anterior and posterior neural fold. Development 122, 3393-3407.

Dickman, E. D., Thaller, C. and Smith, S. M. (1997). Temporally regulated retinoic acid depletion produces specific neural crest, ocular and nervous system defects. Development 124, 3111-3121.

Elshourbagy, N. A., Korman, D. R., Wu, H. L., Sylvester, D. R., Lee, J. A., Nuthalaganti, P., Bergsma, D. J., Kumar, C. S. and Nambi, P. (1993). Molecular characterization and regulation of the human endothelin receptors. J. Biol. Chem. 268, 3873-3879.

Firulli, A. B., McFadden, D. G., Lin, Q., Srivastava, D. and Olson, E. N. (1998). Heart and extra-embryonic mesodermal defects in mouse embryos lacking the bHLH transcription factor Hand1. Nature Genet. 18, 266-270.

Hamburger, V, and Hamilton, H. (1951). A series of normal stages in the development of chick embryo. J. Morphol. 88, 49-92.

Hosoda, K., Hammer, R. E., Richardson, J. A., Baynash, A. G., Cheung, J. C., Giaid, A. and Yanagisawa, M. (1994). Targeted and natural (piebaldlethal) mutations of endothelin-B receptor gene produce megacolon associated with spotted coat color in mice. Cell 79, 1267-1276. 
Iida, K., Koseki, H., Kakinuma, H., Kato, N., Mizutani-Koseki, Y., Ohuchi, H., Yoshioka, H., Noji, S., Kawamura, K., Kataoka, Y., Ueno, F., Taniguchi, M., Yoshida, N., Sugiyama, T. and Miura, N. (1997). Essential roles of the winged helix transcription factor MFH-1 in aortic arch patterning and skeletogenesis. Development 124, 4627-4638.

Inoue, A., Yanagisawa, M., Kimura, S., Kasuya, Y., Miyauchi, T., Goto, K. and Masaki, T. (1989). The human endothelin family: three structurally and pharmacologically distinct isopeptides predicted by three separate genes. Proc. Natl. Acad. Sci. USA 86, 2863-2867.

Karne, S., Jayawickreme, C. K. and Lerner, M. R. (1993). Cloning and characterization of an endothelin-3 specific receptor (ETC receptor) from Xenopus laevis dermal melanophores. J. Biol. Chem. 268, 1912619133.

Kempf, H., le Moullec, J. M., Corvol, P. and Gasc, J. M. (1996). Molecular cloning, expression and tissue distribution of a chicken angiotensin II receptor. FEBS Lett. 399, 198-202.

Kirby, M. L. and Waldo, K. L. (1995). Neural crest and cardiovascular patterning. Circ. Res. 77, 211-215.

Krumlauf, R. (1994). Hox genes in vertebrate development. Cell 78, 191-201.

Kumar, C., Mwangi, V., Nuthulaganti, P., Wu, H. L., Pullen, M., Brun, K., Aiyar, H., Morris, R. A., Naughton, R. and Nambi, P. (1994). Cloning and characterization of a novel endothelin receptor from Xenopus heart. $J$. Biol. Chem. 269, 13414-13420.

Kurihara, Y., Kurihara, H., Suzuki, H., Kodama, T., Maemura, K., Nagai, R., Oda, H., Kuwaki, T., Cao, W. H., Kamada, N., Jishage, K., Ouchi, Y., Azuma, S., Toyada, Y., Ishikawa, T., Kumada, M. and Yazaki, Y. (1994). Elevated blood pressure and craniofacial abnormalities in mice deficient in endothelin-1. Nature 368, 703-710.

Kurihara, Y., Kurihara, H., Oda, H., Maemura, K., Nagai, R., Ishikawa, T. and Yazaki, Y. (1995a). Aortic arch malformations and ventricular septal defect in mice deficient in endothelin-1. J. Clin. Invest. 96, 293300.

Kurihara, Y., Kurihara, H., Maemura, K., Kuwaki, T., Kumada, M. and Yazaki, Y. (1995b). Impaired development of the thyroid and thymus in endothelin-1 knockout mice. J. Cardiovasc. Pharmacol. 26 Suppl 3, S13S16.

Lecoin, L., Sakurai, T., Ngo, M. T., Abe, Y., Yanagisawa, M., Le Douarin, N. M. (1998). Cloning and characterization of a novel endothelin receptor subtype in the avian class. Proc. Natl. Acad. Sci. USA 95, 3024-3029.

Le Douarin, N. M., Dupin, E., Baroffio, A. and Dulac, C. (1992). New insights into the development of neural crest derivatives. Int. Rev. Cytol. 138, 269-314.

Lee, J. E. (1997). Basic helix-loop-helix genes in neural development. Curr. Opin. Neurobiol. 7, 13-20.

Lohnes, D., Mark, M., Mendelsohn, C., Dolle, P., Dierich, A., Gorry, P., Gansmuller, A. and Chambon, P. (1994). Function of the retinoic acid receptors (RARs) during development (I). Craniofacial and skeletal abnormalities in RAR double mutants. Development 120, 2723-2748.

Lumsden, A., Sprawson, N. and Graham, A. (1991). Segmental origin and migration of neural crest cells in the hindbrain region of the chick embryo. Development 113, 1281-91.
Lyons, G. E. (1996). Vertebrate heart development. Curr. Opin. Genet. Dev. 6, 454-460.

Nataf, V., Lecoin, L., Eichmann, A. and Le Douarin, N. M. (1996) Endothelin-B receptor is expressed by neural crest cells in the avian embryo. Proc. Natl. Acad. Sci. USA 93, 9645-9650.

Nataf, V., Grapin-Botton, A., Champeval, D., Amemiya, A., Yanagisawa, M. and Le Douarin, N.M. (1998). The expression patterns of endothelinA receptor and endothelin 1 in the avian embryo. Mech. Dev. (in press).

Richman, J. M. (1992). The role of retinoids in normal and abnormal embryonic craniofacial morphogenesis. Crit. Rev. Oral. Biol. Med. 4, 93109

Sakamoto, A., Yanagisawa, M., Sakurai, T., Takuwa, Y., Yanagisawa, H. and Masaki, T. (1991). Cloning and functional expression of human cDNA for the ETB endothelin receptor. Biochem. Biophys. Res. Commun. 178, 656-663.

Sakurai, T., Yanagisawa, M. and Masaki, T. (1992). Molecular characterization of endothelin receptors. Trends Pharmacol. Sci. 13, 103108

Schilling, T. F. (1997). Genetic analysis of craniofacial development in the vertebrate embryo. BioEssays 19, 459-468.

Schroeder, C., Beug, H. and Muller-Esterl, W. (1997). Cloning and functional characterization of the ornithokinin receptor. Recognition of the major kinin receptor antagonist, HOE140, as a full agonist. J. Biol. Chem. 272, 12475-12481.

Sibony, M., Commo, F., Callard, P. and Gasc, J.-M. (1995). Enhancement of mRNA in situ hybridization signal by microwave heating. Lab. Invest. 73, 586-591.

Srivastava, D., Thomas, T., Lin, Q., Kirby, M. L., Brown, D. and Olson, E. N. (1997). Regulation of cardiac mesodermal and neural crest development by the bHLH transcription factor, dHAND. Nature Genet. 16, 154-160.

Torrens, Y., Daguet de Montety, M. C., EI Etr, M., Beaujouan, J. C. and Glowinski, J. (1989). Tachykinin receptors of the NK1 type (substance P) coupled positively to phospholipase $\mathrm{C}$ on cortical astrocytes from the new born mouse in primary culture. J. Neurochem. 52, 1913-1918.

Waldo, K. L., Kumiski, D. and Kirby, M. L. (1996). Cardiac neural crest is essential for the persistence rather than the formation of an arch artery. Dev Dyn. 205, 281-292.

Yanagisawa, H., Yanagisawa, M., Kapur, R. P., Richardson, J. A. Williams, S. C., Clouthier, D. E., de Wit, D., Emoto, N. and Hammer, R. E. (1998a). Dual genetic pathways of endothelin-mediated intercellular signaling revealed by targeted disruption of endothelin converting enzyme1 gene. Development 125, 825-836.

Yanagisawa, H., Hammer, R. E., Richardson, J. A., Williams, S. C., Clouthier, D. E. and Yanagisawa, M. (1998b). Role of Endothelin1/Endothelin-A receptor-mediated signaling pathway in the aortic arch patterning in mice. J. Clin. Invest. 102, 22-33.

Yanagisawa, N., Kurihara, H., Kimura, S., Tomobe, Y., Kobayashi, M., Mitsui, Y., Yazaki, Y., Goto, K. and Masaki, T. (1988). A novel vasoconstrictor peptide produced by vascular endothelial cells. Nature $\mathbf{3 3 2}$ 411-415. 